\title{
Measuring Disability: An Examination of Differences Between the Washington Group Short Set on Functioning and the American Community Survey Disability Questions
}

\author{
by Julie D. Weeks, Ph.D., James M. Dahlhamer, Ph.D., Jennifer H. Madans, Ph.D., and Aaron Maitland, Ph.D.
}

\section{Abstract}

Objective-This report examines differences in survey reports of disability between two sets of disability questions, the Short Set on Functioning (WG-SS) developed by the Washington Group on Disability Statistics (WG) and a set of disability questions developed for the American Community Survey (ACS).

Methods-Data from the 2011-2012 National Health Interview Survey were used to examine agreement between the WG-SS and ACS measures. One difference between the question sets is the ACS questions have dichotomous "yes" or "no" responses while the WG-SS questions have four answer categories reflecting a continuum of difficulty. Unweighted prevalence estimates of disability and odds ratios are presented for the subset of respondents who provided self-reports to both sets to understand the level of agreement and investigate differences between the two.

Results - Approximately twice as many adults were identified as having disability by the ACS measure compared with the WG-SS measure. This result holds across all subgroups examined. Given the high percentage of respondents reporting no difficulty on both question sets, nonagreement between the two measures is generally low. A variety of sociodemographic and health factors contributed to the observed discordance. While responses of "a lot of difficulty" or "cannot do at all" to the WG-SS questions are highly concordant with "yes" responses to the ACS questions, WG-SS respondents answering "some difficulty" are more likely to have provided "yes" responses to the ACS questions. As a result, the population with disability defined by the ACS questions is more heterogenous in functional level than that defined by the WG-SS questions.

Conclusion-The ACS disability measure identifies a higher percentage of respondents with disability than the WG-SS measure, yet overall agreement between the two measures is high. The WG-SS ordinal response categories allow for an examination of disability severity, which is useful in describing the full continuum of functioning.

Keywords: measurement - functioning - Washington Group on Disability Statistics $•$ National Health Interview Survey (NHIS)

\section{Introduction}

The health status of a population is often reported in terms of the prevalence of diseases or risk factors for these diseases. Determining disease state is important for the development of prevention and treatment interventions. However, having a diagnosed condition is not a comprehensive measure of health, as it does not address the impact of the condition on functional ability. Because functional ability is more closely related to whether an individual can participate in society, it is an important dimension of health status. For example, walking is a key functional domain. Difficulties with walking can affect a child's ability to go to school and an adult's ability to work. Accommodations that address walking difficulties, such as wheelchairs, enable participation despite those difficulties and do so for all causes of the difficulty. Such accommodations also require that the physical environment be appropriately structured. This example illustrates that functioning is not solely a characteristic of a person but involves multiple aspects of society, the principal tenet in the current conceptualization of disability outlined in the World Health Organization's International

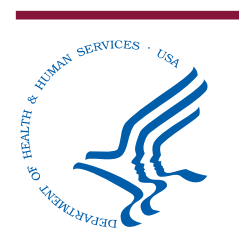


Classification of Functioning, Disability, and Health (ICF) (1).

\section{Disability measurement and data collection}

Information on functioning, and its counterpart disability, was first collected in the 1830 U.S. Census (2) and was a major part of the National Health Interview Survey (NHIS) when originally fielded in 1957 (3). Methods for collecting data on disability have changed over the decades, reflecting how society has conceptualized disability (4). The challenges of collecting information on disability reflect the complexity of the concept. The statistical community, both internationally and in the United States, has worked to improve the collection of information on functioning and disability.

\section{American Community Survey disability questions}

Before 2008, the American Community Survey (ACS) and the 2000 Census questionnaires asked about six disability domains, captured through three questions, each with two subparts. The resulting measure of disability had both conceptual and methodological weaknesses and was considered insufficient by the data user community, advocacy community, and those who shape policies affecting persons with disability (5). As a result, the Office of Management and Budget Interagency Committee for the ACS convened a Subcommittee on Disability Measurement (6) to assess the adequacy of the Census disability questions. The subcommittee, led by the National Center for Health Statistics (NCHS), was open to membership by all federal agencies. One constraint placed on the group was that the amount of space devoted to the new disability questions on the ACS and Census paper forms in use at that time could be no greater than the space used for the existing set; this affected decisions made about the structure of the new questions.

The measure that was developed and extensively tested became known as the "ACS disability measure" (5-7). It comprises six questions with "yes" or "no" response options designed to capture information about basic functioning in core domains and identify the population at risk of disability (Table). These questions were first administered on ACS in 2008. They were also included on other federal surveys, such as the Current Population Survey in 2008, the National Crime Victimization Survey in 2008, NHIS in 2009, and the Survey of Income and Program Participation in 2014. Analyses have shown that the ACS questions identify a population at risk of participation difficulties (8).

\section{Washington Group Short Set on Functioning}

At the same time the ACS disability questions were being developed, the Washington Group on Disability Statistics (WG) had worked to develop a set of disability questions for use worldwide that was designed to improve international comparability of disability statistics. A City Group chartered by the United Nations Statistical Commission, WG comprises experts from national statistical offices who collaborate to address the statistical challenges to collecting valid, reliable, and crossnationally comparable data on disability, and develop methods to improve statistics on persons with disabilities globally. WG first developed a short set of six questions, the WG Short Set on Functioning (WG-SS), which was specifically designed to be used in censuses as well as added to ongoing data collections focused on other topics, such as labor force surveys (Table). WG went on to develop a more comprehensive set of questions for adults, the WG Extended Set on Functioning (WG-ES), which also includes the WG-SS questions, and a Child Functioning Module designed specifically for children.

The WG questions use ICF as a conceptual model and reflect advances in the conceptualization of disability (9). The questions are designed to identify people in the population who are at

Table. Question and response set wording for the American Community Survey and Washington Group Short Set on Functioning disability measures

\begin{tabular}{|c|c|c|c|c|}
\hline Functioning domain & ACS question wording & Response set & WG-SS question wording & Response set \\
\hline Seeing $\ldots \ldots \ldots$. & $\begin{array}{l}\text { Are you blind or do you have serious difficulty seeing } \\
\text { even when wearing glasses? }\end{array}$ & \multirow{5}{*}{$\begin{array}{l}\text { 1. Yes } \\
\text { 2. No }\end{array}$} & $\begin{array}{l}\text { Do you have difficulty seeing, even when } \\
\text { wearing glasses? }\end{array}$ & \multirow{5}{*}{$\begin{array}{l}\text { 1. No difficulty } \\
\text { 2. Some difficulty } \\
\text { 3. A lot of difficulty } \\
\text { 4. Cannot do at all }\end{array}$} \\
\hline Hearing. . . . . . . . & $\begin{array}{l}\text { Are you deaf or do you have serious difficulty } \\
\text { hearing? }\end{array}$ & & $\begin{array}{l}\text { Do you have difficulty hearing, even when } \\
\text { using a hearing aid? }\end{array}$ & \\
\hline Mobility . . . . . . . & $\begin{array}{l}\text { Do you have serious difficulty walking or climbing } \\
\text { stairs? }\end{array}$ & & $\begin{array}{l}\text { Do you have difficulty walking or climbing } \\
\text { stairs? }\end{array}$ & \\
\hline Cognition $\ldots \ldots \ldots$ & $\begin{array}{l}\text { Because of a physical, mental, or emotional } \\
\text { condition, do you have serious difficulty } \\
\text { concentrating, remembering, or making decisions? }\end{array}$ & & $\begin{array}{l}\text { Do you have difficulty remembering or } \\
\text { concentrating? }\end{array}$ & \\
\hline Self care ........ & Do you have difficulty dressing or bathing? & & $\begin{array}{l}\text { Do you have difficulty (with self care such as) } \\
\text { washing all over or dressing? }\end{array}$ & \\
\hline Independence. . . . . & $\begin{array}{l}\text { Because of a physical, mental, or emotional } \\
\text { condition, do you have difficulty doing errands alone, } \\
\text { such as visiting a doctor's office or shopping? }\end{array}$ & & $\cdots$ & $\cdots$ \\
\hline Communication. . . . & $\cdots$ & $\cdots$ & $\begin{array}{l}\text { Using your usual (customary) language, } \\
\text { do you have difficulty communicating, for } \\
\text { example, understanding or being understood? }\end{array}$ & $\begin{array}{l}\text { 1. No difficulty } \\
\text { 2. Some difficulty } \\
\text { 3. A lot of difficulty } \\
\text { 4. Cannot do at all }\end{array}$ \\
\hline
\end{tabular}

... Category not applicable.

NOTES: ACS is American Community Survey. WG-SS is Washington Group Short Set on Functioning.

SOURCES: American Community Survey (https://www.census.gov/topics/health/disability/guidance/data-collection-acs.html) and Washington Group Short Set on Functioning (https://www.washingtongroup-disability.com/). 
greater risk than the general population of experiencing limited or restricted participation in society. Question testing has shown that WG questions produce internationally comparable data (10). WG-SS has been recommended by both the United Nations (UN) Statistical Division and the UN Economic Commission for Europe's Conference of European Statisticians as the preferred method for collecting information on disability in the current 2020 round of censuses. The question set has also been endorsed as the international standard for disaggregating the 2030 Agenda for Sustainable Development Goals by disability status and has been added to surveys and data collections worldwide, including the National Health and Nutrition Examination Survey, National Survey of Family Growth, and NHIS (11).

\section{ACS and WG-SS in NHIS}

From its inception, one of the primary purposes of NHIS is to collect information on functioning and disability. The ACS questions have been included in NHIS since 2009. WG-SS and WG-ES have also been included in NHIS since 2010 to provide the greater detail on functional status required for a health survey. After several years of including both ACS and WG questions on NHIS, NCHS shifted away from asking the ACS questions and began asking only the WG questions to measure disability on NHIS starting in 2019 as part of its questionnaire redesign (12).

The WG-SS and ACS questions take the same approach to measuring disability: Both focus on the ascertainment of functional status in similar core domains of functioning. The main difference is in the answer categories used. The ACS questions use a dichotomous "yes" or "no" response set, which was dictated by the space constraints on the paper forms used by the Census and ACS at the time they were adopted. The WG-SS questions use an ordinal response set to better capture different levels of severity and, thus, greater granularity in functional ability. The response options are: no difficulty, some difficulty, a lot of difficulty, or cannot do at all. This difference may result in the identification of somewhat different populations. Previous research using data from the 2010 and 2013-2015 NHIS found that both measures generally identify the population with disability with similar distributions of demographic characteristics; however, the prevalence of disability is higher for the ACS measure compared with the WG measure (13).

Both the ACS and WG measures are important sources of information on functioning and disability, so it is critical to understand the differences in the estimates produced by each. In the 2011 and 2012 NHIS, a subset of respondents received both the ACS and WG-SS question sets, thus allowing for a direct comparison of responses to the two measures.

This report presents analyses from data collected from that group of adult respondents to the 2011-2012 NHIS who answered both the ACS and WG-SS disability questions. These data provide a unique opportunity to compare answers to the two different questions sets and provide a better understanding of the key similarities and differences between the two measures.

\section{Methods}

\section{Data source}

Data from the 2011 and 2012 NHIS were used to generate the estimates presented in this report (14-15). NHIS is an annual multipurpose health survey conducted continuously throughout the year and serves as a primary source of health data on the civilian noninstitutionalized population of the United States. Data are collected by trained U.S. Census Bureau interviewers using computer-assisted personal interviewing, a data collection method in which an interviewer meets with respondents face to face to ask questions and enters the answers into a laptop computer. When necessary, interviewers may complete missing portions of the interview over the telephone.

For the data years analyzed, NHIS had four main interview modules: the Household Composition Section, Family Core, Sample Adult Core, and
Sample Child Core. The Household Composition Section of the questionnaire collected basic demographic and relationship information about all people in the household. The Family Core questionnaire, which was administered separately for each family in the household, collected information on all people in the family, and covered topics such as sociodemographic characteristics, basic indicators of health status, health insurance coverage, and access to and use of health care services. From each participating family, one sample child (if there were children aged 17 years and under) and one sample adult aged 18 years and over were randomly selected, and information on each was collected with the Sample Child and Sample Adult questionnaires, respectively. The Sample Adult Core interview collected data on health status and conditions, health behaviors, functioning and disability, and access to and utilization of health care services. Sample adults answer for themselves, unless they are mentally or physically unable to do so; in that case, a knowledgeable adult serves as a proxy respondent.

Analyses in this report were based on data collected from the 18,079 sample adults aged 18 and over who were also the family respondent and who were asked both the ACS questions and WG questions. The ACS questions appeared at the end of the Family Core questionnaire, in the Family Disability Questions Test section, where the family respondent answered the questions for themselves and all other family members. The WG questions appeared at the end of the Sample Adult questionnaire in the Adult Functioning and Disability section. Because the family interview must be completed before the sample adult interview, the ACS questions were always asked before the WG questions. The analyses were restricted to those sample adults who were also family interview respondents to ensure that responses to both sets of questions were self-reported.

\section{Measures}

The WG and ACS sets each include six questions, with each question covering a single domain of functioning. Five of the functional domains are 
the same in WG and ACS, and the questions from these domains that obtain information on the same underlying concepts are used in the analysis reported herein (Table). The ACS questions use a "yes" or "no" response option format. To ensure the questions capture a more functionally limited population, the phrase "serious difficulty" is included in the question stem text for all questions, with the exception of the self care item. The WG questions use a response scale designed to capture the degree or severity of difficulty experienced: no difficulty, some difficulty, a lot of difficulty, cannot do at all.

For this report, overall, dichotomous indicators of disability were created using the five questions from the comparable ACS and WG domains. A sample adult who answered "yes" to any of the five ACS questions was classified as having disability; sample adults who responded "no" to all five ACS questions were classified as not having disability. Adults with a mix of "no" responses, "don't know" responses, or "refused" responses were treated as missing, resulting in the loss of five cases. For the WG questions, a sample adult who answered "a lot of difficulty" or "cannot do at all" to any of the five questions was classified as having disability. Responses of "no difficulty" or "some difficulty" to all five questions were classified as no disability. Adults with one or more "don't know" or "refused" responses, but no responses of "a lot of difficulty" or "cannot do at all" were treated as missing, resulting in the loss of 61 cases.

Given the ordinal response scale used with the WG questions, various definitions of disability status can be created. A trichotomous measure of disability status based on the WG questions was used for a subset of the analyses. For this trichotomous measure, sample adults who answered, "a lot of difficulty" or "cannot do at all" to any of the five questions were coded as with disability, consistent with the dichotomous measure and the coding recommendations provided by WG. Unlike the dichotomous measure, however, a more precise no disability category that captures sample adults who answered "no difficulty" to all five questions could be created. The remaining sample adults who answered "some difficulty" to at least one question, but did not answer "a lot of difficulty" or "cannot do at all" to any of the five questions were placed in a third "some difficulty" category.

Prevalence estimates of disability are presented for subgroups defined by a set of selected sociodemographic and health measures. The characteristics of adults identified as having disability using each indicator are also presented using the same set of select sociodemographic and health measures. Sociodemographic measures include age (18-44, 45-64, or 65 and over), sex, race and ethnicity (Hispanic, non-Hispanic white, non-Hispanic black, or non-Hispanic other), education (less than high school, high school diploma or GED, some college or associate's degree, or bachelor's degree or higher), employment status (employed or not employed), marital status (never married; married or living with partner; or divorced, separated, or widowed), whether the residence is owned or being bought or rented or some other arrangement, and poverty status (less than $100 \%$ of the federal poverty level, $100 \%-199 \%$ of the federal poverty level, $200 \%-399 \%$ of the federal poverty level, or $400 \%$ or more of the federal poverty level). Poverty status was calculated using NHIS imputed income files. Health measures include reported health status (poor or fair, good, or very good or excellent), whether or not the sample adult is limited in any way because of difficulty remembering or because they experience periods of confusion (a question asked in the Family Core questionnaire before both the ACS and WG questions), whether or not the sample adult experienced serious psychological distress in the past 30 days, and whether or not the sample adult has two or more chronic conditions (coronary heart disease, stroke, hypertension, diabetes, cancer, chronic obstructive pulmonary disease, weak or failing kidneys, arthritis, and hepatitis). Serious psychological distress is based on responses to six questions that ask how often a respondent experienced the following symptoms in the past 30 days: feeling so sad nothing could cheer you up; nervous; restless or fidgety; hopeless; that everything was an effort; and worthless. The response codes $(0-4)$ of the six items are summed to yield a scale with a $0-24$ range, with a value greater than or equal to 13 indicating serious psychological distress.

In addition to the sociodemographic and health measures described above, a set of interview process variables were included in the analyses: mode of interview (both sets of questions asked face to face, both sets of questions asked over the telephone, or other), language of interview (English or other), and speeding through either or both sets of questions (speeding through the ACS questions, speeding through the WG questions, or speeding through both sets of questions). Speeding was defined as spending less than 10 seconds on the five ACS questions and less than 13 seconds on the WG questions. Both thresholds represent the 10th percentile of the respective time distributions.

Finally, a select set of sociodemographic measures and health outcomes were included in concurrent validity assessments of both disability indicators: whether or not the sample adult was unemployed (among adults aged 18-64); whether or not the sample adult had less than a high school education (among adults aged 25 and over); whether or not the sample adult rents their residence; and whether or not the sample adult's total family income for the prior calendar year was below the federal poverty level.

\section{Statistical analysis}

First, sample adults who answered both the ACS and WG-SS disability questions were compared on a set of sociodemographic, health, and interview process variables to all sample adults using a nested $t$ test to account for the overlap in the two sets of cases. This analysis provides some indication of whether the subset of sample adults who received both sets of disability questions and are used as the analytic sample in this report differ from the full NHIS sample.

Second, estimates of disability (and 95\% confidence intervals [CIs]) based on the two question sets were calculated overall and by a set of sociodemographic, health, and interview process variables. The ratios of the ACS to WG-SS 
estimates are also presented to show the magnitude of difference between the two estimates overall and by subgroup.

Third, distributions of these same sociodemographic, health, and interview process measures are compared for two groups of adults with disability, one based on the ACS questions and the other based on the WG-SS questions, to identify differences across these characteristics in the populations identified with each disability set. Differences between percentages for the two groups were evaluated using two-tailed significance tests at the 0.05 level. The reported $p$ values of these tests are conservative, as they did not account for the overlap or covariance between the two groups of adults with disability. Hence, differences in characteristics of adults as defined by these two measures of disability are likely to be underestimated. No adjustments were made for multiple comparisons.

Fourth, a simple crosstabulation of the two disability measures along with a set of statistics measuring agreement are presented, including overall agreement, positive agreement, negative agreement, simple kappa, and the prevalenceadjusted bias-adjusted kappa (PABAK). The PABAK is presented because the marginal totals for the $2 \times 2$ table in which the two disability measures are crossed are imbalanced (the prevalence of disability on both measures is very low). Therefore, the value provided by a simple kappa may indicate a low level of reliability even when the observed proportion of agreement between the two disability measures is quite high (16).

Fifth, nonagreement between the two disability measures in a multivariate context is explored. A binary logistic regression in which the dependent variable is agreement compared with nonagreement is estimated including the sociodemographic, health, and interview process variables described earlier (age, sex, race and ethnicity, education, employment status, marital status, home ownership, poverty status, reported health status, limitation because of difficulty remembering or confusion, experience of serious psychological distress, having two or more chronic conditions, language of interview, mode of interview, and speeding through the questions). The binomial logistic regression is then extended by estimating a multinomial logistic regression in which nonagreement is split into the following: "with disability" as defined by the ACS measure but "no disability" as defined by the WG-SS measure, and "with disability" as defined by WG-SS but "no disability" as defined by the ACS measure. Hence, the dependent variable is trichotomous with each form of nonagreement compared with agreement. The covariates included in the multinomial logistic regression are the same as those used with the binomial logistic regression. For both the binary and multinomial logistic regressions, adjusted odds ratios (AORs) and 95\% CIs are shown.

Sixth, the dichotomous ACS measure of disability and the trichotomous WG-SS measure are crosstabulated to better illustrate the nonagreement by severity of disability.

Finally, each disability measure is assessed with regard to concurrent validity. This analysis examines the extent to which each measure is related to selected outcomes of interest (unemployment, having less than a high school education, home ownership, and poverty status). For each outcome, three bivariate logistic regressions were estimated with different measures of disability as the independent variables; one with the dichotomous ACS disability measure (no disability as the reference category), one with the dichotomous WG-SS disability measure (no disability as the reference category), and one using the trichotomous WG-SS disability measure (with disability compared with no difficulty and some difficulty compared with no difficulty). The unadjusted odds ratio from each model is presented as a measure of the strength of association between the disability measure and the outcome of interest.

Estimates of disability overall and by subgroups, select sociodemographic and health estimates among adults with disability, estimates of agreement between the two disability measures, and assessments of concurrent validity were all performed using SAS SURVEY PROCEDURES within SAS software, Version 9.4 (SAS Institute Inc., Cary, N.C.). Logistic regression models of agreement were performed in
SAS-callable SUDAAN, version 11.0.3 software (RTI International, Research Triangle Park, N.C.). All procedures accounted for the stratified, complex cluster sampling design of NHIS. As the objective of the analysis is to understand the relationship between the two question sets and not to make nationally representative estimates of disability, all analyses were unweighted.

\section{Results}

Table 1 compares the demographic distribution for the analytic sample with the demographic distribution of all sample adults. It shows several statistically significant results using a nested $t$ test; however, most of these differences are substantively quite small. There were only a few variables in the table with a difference of two or more percentage points. For example, the ACS-WG sample included a higher percentage of adults who are female, not working, and renting their home compared with the full sample of adults from 2011 and 2012. The ACS-WG sample included a lower percentage of adults who are married and lower percentage of cases who completed the NHIS family interview and sample adult interview in different modes compared with the full sample of adults from 2011 and 2012.

\section{Prevalence of disability across measures}

Table 2 shows the percentage with disability according to each measure overall and by different subgroups. Overall, the table shows that the ACS measure produced percentages that are 2.1 times the percentages of $\mathrm{WG}-\mathrm{SS}$. There are some characteristics where the percentage of adults with ACS disability was approximately three times that of adults with WG-SS disability. For example, the percentage of employed respondents with ACS disability was $8.2 \%$ compared with $2.7 \%$ for those identified with disability using WG-SS. Among adults whose family income is $400 \%$ or more of the federal poverty level, the percentage of adults who were identified with disability was $12.9 \%$ 
for the ACS measure compared with $5.2 \%$ for WG-SS. Finally, among adults in very good or excellent health, the percentage of those with ACS disability was $8.2 \%$ compared with $2.8 \%$ using WG-SS.

\section{Profile of adults with disability}

Table 3 is a profile of the respondents who are classified with disability by the WG-SS and ACS measures. Adults identified with ACS disability were significantly more likely to be aged 18-44 and less likely to be aged 65 and over compared with respondents identified by WG-SS. There was also a higher percentage of males (39.7\%) identified by the ACS measure compared with WG-SS (34.1\%). Adults identified as having a disability with the ACS measure were less likely to be Hispanic and more likely to be non-Hispanic white compared with WG-SS. Adults identified as having a disability with the ACS measure were more likely to be married (28.6\%) compared with WG-SS (26.5\%). Adults identified as having a disability with the ACS measure were more likely to be veterans $(15.0 \%)$ compared with WG-SS (12.8\%). Adults identified as having a disability with the ACS measure were less likely to be foreign born and less likely to use a language other than English during the interview compared with WG-SS.

Adults identified as having a disability by the ACS measure generally had higher socioeconomic status compared with adults identified as having disability by WG-SS. Compared with adults with disability as defined by WG-SS, adults identified by the ACS measure were more likely to be employed ( $22.4 \%$ compared with $15.5 \%$ ), less likely to have less than a high school education (26.6\% compared with $30.3 \%$ ), but were also more likely to have a bachelor's degree (14.6\% compared with $11.6 \%$ ). There were also differences by poverty status, with $27.2 \%$ of adults identified as having disability by the ACS measure with family income below $100 \%$ of the federal poverty level compared with $29.5 \%$ of adults identified by WG-SS. A higher percentage of adults identified as having disability by the ACS measure own their home $(51.6 \%)$ compared with adults identified by WG-SS (46.3\%).

Adults identified as having disability by the ACS questions tended to be in better health than adults identified as having disability by WG-SS. The ACS measure included a lower percentage of adults in poor or fair health $(46.7 \%)$ compared with WG-SS (57.6\%) and a lower percentage of adults with multiple chronic conditions $(63.5 \%)$ compared with the WG-SS measure (71.1\%). The ACS measure also identified a lower percentage of adults with serious psychological distress (12.2\%) compared with the WG measure (16.9\%). The ACS measure also included a lower percentage of adults with cognitive difficulty $(20.0 \%)$ compared with the WG measure (24.6\%).

Adults identified as having a disability by the ACS questions were more likely to speed through the WG questions $(2.6 \%)$ compared with adults identified by WG-SS ( $0.9 \%)$.

\section{Agreement and nonagreement}

Because the 2011 and 2012

NHIS repeated both the ACS and WG questions on the same respondents, the extent to which the two measures classify the same respondents into the same disability status was examined. Table 4 illustrates that approximately $87 \%$ of the respondents were classified into the same disability status across the two indicators. This included 8.7\% $(n=1,557)$ who were classified as having disability by both the ACS and WG-SS measures and $78.4 \%(n=14,108)$ who were classified as not having disability by both measures. Approximately 13\% of the sample were classified differently by the two measures. This included $11.8 \%(n=2,125)$ who were classified as having disability according to the ACS measure but not WG-SS. Approximately $1.1 \%(n=195)$ were classified as having disability according to the WG measure but not the ACS measure. The kappa statistic (0.50) indicated moderate agreement and the PABAK (0.74) indicated substantial agreement. The results in Table 4 were consistent with the results in Table 2 showing that among those classified differently on the two measures, more respondents were classified as having disability by the ACS measure than the WG-SS measure.

\section{Correlates of nonagreement}

Binomial and multinomial logistic regression models predicting nonagreement between the ACS and WG-SS disability indicators were estimated and are presented in Table 5. The results of the binomial logistic regression model for overall nonagreement are first described. Several demographic characteristics are related to nonagreement in disability status between the ACS and WG-SS questions. The odds of overall nonagreement were higher for respondents between the ages of 45-64 $(\mathrm{AOR}=1.58,95 \% \mathrm{CI}=1.37-1.82)$ and 65 and over $(\mathrm{AOR}=1.96$, $95 \% \mathrm{CI}=1.65-2.33)$ relative to those aged 18-44. Females had lower odds of overall nonagreement than males $(\mathrm{AOR}=0.90,95 \% \mathrm{CI}=0.81-1.00)$. Non-Hispanic other adults had lower odds of nonagreement compared with non-Hispanic white adults $(\mathrm{AOR}=0.77$, $95 \% \mathrm{CI}=0.61-0.97)$.

The odds of nonagreement were higher for respondents with lower socioeconomic status. For example, relative to adults with a bachelor's degree, the odds of nonagreement were higher for adults with less than a high school education $(\mathrm{AOR}=1.44$, 95\% CI = 1.21-1.72), a high school diploma or GED $(\mathrm{AOR}=1.21$, $95 \% \mathrm{CI}=1.04-1.40)$, and some college or associate's degree $(\mathrm{AOR}=1.35$, $95 \% \mathrm{CI}=1.17-1.55)$. Adults who were not employed had higher odds of overall nonagreement than those who were employed $(\mathrm{AOR}=1.63$, $95 \% \mathrm{CI}=1.45-1.85)$. Adults with family income of less than $100 \%$ of the federal poverty level had higher odds of nonagreement relative to adults with family income of $400 \%$ or more of the federal poverty level $(\mathrm{AOR}=1.23,95 \% \mathrm{CI}=1.05-1.45)$. The odds of overall nonagreement were also more likely for adults who reported poor or fair health $(\mathrm{AOR}=2.55$, 95\% CI $=2.21-2.94)$ and good health $(\mathrm{AOR}=1.99,95 \% \mathrm{CI}=1.76-2.24)$ relative to those who reported very good or excellent health. The odds of overall 
nonagreement were higher for adults with cognitive difficulty ( $\mathrm{AOR}=1.82$, $95 \% \mathrm{CI}=1.51-2.19)$ and adults with multiple chronic conditions $(\mathrm{AOR}=1.47$, $95 \% \mathrm{CI}=1.31-1.66)$.

The models in Table 5 also include controls for language of interview, mode of interview, and speeding through the questions. Speeding was associated with nonagreement between ACS and WG-SS. When speeding occurred on only one set of questions, the odds of nonagreement were lower than when no speeding occurred. When speeding occurred on both sets of questions, the odds of nonagreement were higher.

The multinomial logistic regression model results for specific nonagreement were largely consistent with the binomial model for overall nonagreement with a couple of exceptions. Relative to males, females had higher odds of not having a disability on the ACS questions and being identified as having a disability on $\mathrm{WG}-\mathrm{SS}$ (AOR $=1.48$, 95\% CI = 1.00-2.19); however, females had lower odds of being identified as having a disability on the ACS questions and not having a disability on WG-SS (AOR $=0.85,95 \% \mathrm{CI}=0.76-0.95)$. Relative to respondents who did not speed on either version of the questions, respondents who were speeding on WG-SS had higher odds of not having a disability on the ACS questions and being identified as having a disability on WG-SS $(\mathrm{AOR}=20.14$, 95\% CI = 2.73-148.9); however, respondents who were speeding on WG-SS had lower odds of being identified as having a disability on the ACS questions and not having a disability on $\mathrm{WG}-\mathrm{SS}(\mathrm{AOR}=0.35$, $95 \% \mathrm{CI}=0.23-0.52)$.

\section{Impact of response categories}

The use of ordinal rather than dichotomous response categories on the WG-SS questions is one potential source of nonagreement between the ACS and WG-SS measures of disability. Ordinal response categories give the analyst an opportunity to classify respondents into different levels of severity of their functioning and disability. The first column in Table 6 shows that the WG-SS measure used in this report classified 1,752 adults as having disability, because they reported "a lot of difficulty" or "cannot do at all" for at least one of the five functioning domains when responding to the WG-SS questions. The second row of Table 6 also shows that 2,125 of the 3,682 adults $(57.7 \%)$ who were classified as having disability by the ACS measure were not classified as having disability by WG-SS because they reported either "some difficulty" ( $n=1,801)$ or "no difficulty" $(n=324)$ in all five functioning domains. One source of nonagreement between the two measures is their differential ability to distinguish between different levels of the severity of disability (for example, some difficulty compared with a lot of difficulty). Table 6 shows that 1,801 $(84.7 \%)$ of the 2,125 adults who are classified as having disability by the ACS measure but not by WG-SS $(1,801$ with some difficulty plus 324 with no difficulty) reported some difficulty in at least one of the five domains when responding to the WG questions. Hence, the nonagreement between the two dichotomous disability measures appears to be driven in large part by adults with "some disability."

\section{Concurrent validity}

To assess the concurrent validity of each disability measure, the extent of the correlation between each measure and other measures known to be associated with disability status was analyzed. One of the analytical objectives of including disability questions on censuses and surveys is to determine whether those with disability are able to participate in society to the same extent as those without disability. Disability can increase the risk of experiencing restrictions in performing specific tasks or participating in role activities. These restrictions may lead to persons with disability being disadvantaged on a variety of socioeconomic outcomes such as employment, education, home ownership, and poverty status.

Table 7 shows the strength of the association between different measures of disability and selected socioeconomic outcomes. The odds ratios in Table 7 represent the odds of adults who are classified as having disability experiencing each outcome relative to adults who are not classified as having disability according to each of the specific disability measures investigated. Table 7 columns 1 (ACS measure) and 2 (WG-SS dichotomous measure) illustrate that both disability measures are related to the selected outcomes. Table 7 also shows that the odds are consistently higher for the WG measure compared with the ACS measure. For example, the odds of unemployment were 5.40 using the ACS measure but were 7.43 using the WG-SS dichotomous measure. The pattern of the higher odds ratios for the WG-SS measure was similar for the other outcomes in Table 7. The final two columns of the table show the odds of each outcome for specific categories of the WG-SS measure. These final two columns of the table demonstrate that the odds of each outcome are higher for adults who answered "a lot of difficulty" or "cannot do at all" on at least one of the WG-SS questions compared with the odds of those who answered "some difficulty" on at least one of the WG-SS questions (but answered "a lot of difficulty" or "cannot do at all" on none of the five questions). For example, the odds of unemployment for those experiencing some difficulty compared with no difficulty were 1.97 , but the odds of those experiencing a lot of difficulty versus no difficulty were 8.94 .

\section{Discussion}

Overall agreement between the ACS and WG-SS measures is moderate to substantial depending on the statistics used, reflecting the high agreement among those reporting no disability on both question sets. One noticeable difference between the two measures is that the ACS measure identifies approximately twice as many adults with disability in the sample than the WG-SS measure; this ratio holds across subgroups as well.

The WG-SS measure tended to include a higher percentage of respondents who may be at increased risk of experiencing restrictions in social participation, as defined based on a set of socioeconomic indicators. For example, adults identified as having 
disability by WG-SS were more likely to have lower socioeconomic status on a variety of measures compared with respondents identified by the ACS measure. In addition, $48.9 \%$ of adults who were identified as having disability on the ACS measure answered only "some difficulty" in one of the five functioning domains on the WG-SS questions and thus were not classified as having disability by WG-SS. Taken together, this indicates that WG-SS may be more effective at identifying a more homogeneous population with higher levels of functional difficulty and lower levels of socioeconomic status that could make them more likely to experience restrictions in social participation as well as a population with lower levels of functional difficulty who experience lower levels of restrictions.

While the design of the 2011-2012 NHIS had the advantage of being able to classify the same set of respondents on both measures, there are some limitations to the data. Because the WG-SS questions were always asked sometime after the ACS questions in the interview, it is possible that interviewers may have assumed the answers were the same across both sets of questions, lowering the odds of nonagreement. For example, respondents were asked the ACS questions toward the beginning of the interview and the WG-SS questions toward the end of the interview. The similarity of the two sets of questions could potentially annoy respondents and encourage interviewers to record answers without completely asking all the questions. This methodological artifact is controlled for in the multivariate models examining nonagreement by identifying respondents who were speeding through the questions.

WG-SS will continue to be asked on NHIS following the 2019 NHIS content redesign, and in other federal data collections, but the ACS measure is still included in other surveys. The continued inclusion of WG-SS on a major federal health survey like NHIS will provide information not available from surveys using the ACS questions. First, WG-SS allows for greater granularity in describing the impact of functional difficulties on participation in society. Their inclusion also facilitates international comparisons with other countries that are asking the WG questions. International comparison was a major motivation for the development of the WG-SS questions. Finally, WG-SS can be supplemented with the additional questions collected as part of the WG-ES, which is also included on NHIS, to further understand the population with disability. The results reported here will allow users to crosswalk between surveys using the WG-SS or ACS questions.

\section{References}

1. World Health Organization. International classification of functioning, disability and health (ICF). Geneva, Switzerland. 2001.

2. U.S. Census Bureau. Why we ask questions about...disability. Available from: https://www.census.gov/acs/ www/about/why-we-ask-eachquestion/disability/.

3. National Center for Health Statistics. Origin, program, and operation of the U.S. National Health Interview Survey. Vital Health Stat 1(1). 1963.

4. Altman B. Disability definitions, models, classification schemes, and applications. In: Albredht GL, Seelman KD, Bury M, editors. Handbook of Disability Studies. Thousand Oaks, CA: Sage Publications, 97-122. 2001.

5. Brault MW, Stern S. Evaluation report covering disability. U.S. Census Bureau. 2007. Available from: https:// www.census.gov/content/dam/ Census/library/working-papers/2007/ acs/2007_Brault_01.pdf.

6. Brault MW. Review of changes to the measurement of disability in the 2008 American Community Survey. U.S. Census Bureau. 2009. Available from: https://www.census.gov/content/dam/ Census/library/working-papers/2009/ demo/2008acs-disability.pdf.

7. Miller K, DeMaio TJ. Report of cognitive research on proposed American Community Survey disability questions. U.S. Census Bureau. 2006. Available from: https:// www.census.gov/content/dam/ Census/library/working-papers/2006/ adrm/ssm2006-06.pdf.
8. Altman BM, Madans J, Weeks JD. An evaluation of the American Community Survey indicators of disability. Disabil Health J 10(4):485-91. 2017.

9. Madans JH, Loeb ME, Altman BM. Measuring disability and monitoring the UN Convention on the Rights of Persons with Disabilities: The work of the Washington Group on Disability Statistics. BMC Public Health 11(Suppl 4):S4. 2011.

10. Miller K, Mont D, Maitland A, Altman B, Madans J. Results of a cross-national structured cognitive interviewing protocol to test measures of disability. Qual Quant 45:801-15. 2011.

11. Washington Group on Disability Statistics. An introduction to the Washington Group on Disability Statistics question sets. 2020. Available from: https://www.washingtongroupdisability.com/fileadmin/uploads/wg/ Documents/Primer.pdf.

12. Weeks JD. Disability statistics at NCHS: An update on 2019 activities. 2018 Annual Disability Statistics Meeting. The National Academies of Science. Washington, DC. 2019. Available from: https:// disabilitycompendium.org/archives.

13. Lauer EA, Henly M, Coleman R. Comparing estimates of disability prevalence using federal and international disability measures in national surveillance. Disabil Health J 12(2):195-202. 2019.

14. National Center for Health Statistics. National Health Interview Survey: Survey description, 2011. Hyattsville, MD. 2012.

15. National Center for Health Statistics. National Health Interview Survey: Survey description, 2012. Hyattsville, MD. 2013.

16. Byrt T, Bishop J, Carlin JB. Bias, prevalence and kappa. J Clin Epidemiol 46(5):423-29. 1993. 
Table 1. Comparison of American Community Survey and Washington Group Short Set on Functioning sample adults with all sample adults (unweighted)

\begin{tabular}{|c|c|c|c|c|c|c|c|c|}
\hline \multirow[b]{2}{*}{ Variable } & \multicolumn{4}{|c|}{ ACS and WG-SS sample adults $(n=18,079)$} & \multicolumn{4}{|c|}{ All sample adults $(n=66,606)$} \\
\hline & Number & Percent & $95 \% \mathrm{Cl}$ & SE & Number & Percent & $95 \% \mathrm{Cl}$ & SE \\
\hline \multicolumn{9}{|l|}{ Age group } \\
\hline $18-44 \ldots \ldots \ldots \ldots \ldots \ldots \ldots \ldots \ldots \ldots$ & 7,870 & $\dagger 43.5$ & $42.4-44.6$ & 0.51 & 30,064 & 45.1 & $44.5-45.8$ & 0.35 \\
\hline 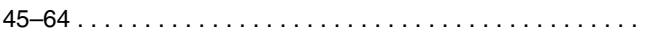 & 6,188 & 34.2 & $33.0-35.4$ & 0.41 & 22,734 & 34.1 & $33.5-34.8$ & 0.24 \\
\hline 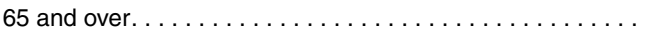 & 4,021 & $\dagger 22.2$ & $21.0-23.6$ & 0.39 & 13,808 & 20.7 & $20.1-21.4$ & 0.25 \\
\hline \multicolumn{9}{|l|}{ Sex } \\
\hline Male ... & 7,506 & $\dagger 41.5$ & $40.4-42.6$ & 0.38 & 29,613 & 44.5 & $43.9-45.0$ & 0.21 \\
\hline 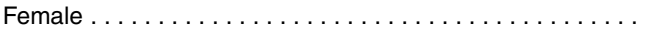 & 10,573 & $\dagger 58.5$ & $57.5-59.4$ & 0.38 & 36,993 & 55.5 & $55.0-56.0$ & 0.21 \\
\hline \multicolumn{9}{|l|}{ Hispanic origin and race } \\
\hline Hispanic $\ldots \ldots \ldots \ldots \ldots \ldots \ldots \ldots$ & 2,923 & $\dagger 16.2$ & $14.9-17.6$ & 0.37 & 11,575 & 17.4 & $16.7-18.1$ & 0.31 \\
\hline Non-Hispanic white. $\ldots \ldots \ldots \ldots \ldots \ldots \ldots \ldots$ & 10,900 & 60.3 & $59.3-61.3$ & 0.51 & 39,618 & 59.5 & $58.6-60.3$ & 0.44 \\
\hline 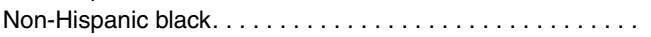 & 2,867 & $\dagger 15.9$ & $14.5-17.2$ & 0.40 & 9,836 & 14.8 & $14.1-15.5$ & 0.29 \\
\hline Non-Hispanic, other races $\ldots \ldots \ldots \ldots \ldots \ldots \ldots$ & 1,389 & 7.7 & $6.3-9.2$ & 0.32 & 5,577 & 8.4 & 7.7-9.1 & 0.35 \\
\hline \multicolumn{9}{|l|}{ Education } \\
\hline Less than high school. . . . . . . . . . . . . . . . & 2,816 & 15.6 & $14.3-17.0$ & 0.35 & 10,592 & 16.0 & $15.3-16.7$ & 0.25 \\
\hline High school diploma or GED $\ldots \ldots \ldots \ldots \ldots \ldots \ldots \ldots$ & 4,438 & $\dagger 24.6$ & 23.3-25.9 & 0.39 & 17,103 & 25.8 & $25.1-26.4$ & 0.27 \\
\hline Some college or associate's degree $\ldots \ldots \ldots \ldots \ldots \ldots$ & 5,770 & †32.0 & $30.8-33.2$ & 0.40 & 20,500 & 30.9 & $30.3-31.5$ & 0.25 \\
\hline Bachelor's degree or higher $\ldots \ldots \ldots \ldots \ldots \ldots \ldots$ & 5,012 & 27.8 & $26.6-29.1$ & 0.47 & 18,133 & 27.3 & $26.7-28.0$ & 0.35 \\
\hline \multicolumn{9}{|l|}{ Employment status } \\
\hline Employed .... . & 10,134 & $\dagger 56.1$ & $55.1-57.0$ & 0.44 & 38,885 & 58.4 & $57.8-58.9$ & 0.29 \\
\hline Not employed . . . . . . . . & 7,927 & $\dagger 43.9$ & $42.9-45.1$ & 0.44 & 27,656 & 41.6 & $41.0-42.2$ & 0.29 \\
\hline \multicolumn{9}{|l|}{ Poverty status } \\
\hline Less than $100 \%$ FPL $\ldots \ldots \ldots \ldots$ & 3,598 & $\dagger 19.9$ & $18.6-21.2$ & 0.38 & 12,073 & 18.1 & $17.4-18.8$ & 0.24 \\
\hline $100 \%-199 \%$ FPL $\ldots$. & 3,895 & 21.5 & $20.3-22.9$ & 0.35 & 13,996 & 21.0 & $20.3-21.7$ & 0.22 \\
\hline$\ldots \ldots \ldots \ldots \ldots \ldots \ldots$ & 5,191 & 28.7 & $27.5-30.0$ & 0.36 & 19,457 & 29.2 & 28.6-29.9 & 0.21 \\
\hline $400 \%$ or more $\mathrm{FPL} \ldots \ldots \ldots \ldots \ldots \ldots \ldots \ldots$ & 5,395 & $\dagger 29.8$ & $28.6-31.1$ & 0.43 & 21,080 & 31.7 & $31.0-32.3$ & 0.30 \\
\hline \multicolumn{9}{|l|}{ Marital status } \\
\hline Never married $\ldots \ldots \ldots \ldots \ldots \ldots \ldots \ldots \ldots$ & 4,725 & $\dagger 26.2$ & $25.0-27.5$ & 0.47 & 15,783 & 23.7 & 23.1-24.4 & 0.30 \\
\hline Married or living with partner $\ldots \ldots \ldots \ldots \ldots \ldots$ & 7,197 & †39.9 & $38.8-41.1$ & 0.43 & 33,154 & 49.9 & $49.3-50.5$ & 0.30 \\
\hline Divorced, separated, or widowed $\ldots \ldots \ldots \ldots \ldots \ldots \ldots$ & 6,102 & $\dagger 33.9$ & $32.7-35.1$ & 0.42 & 17,520 & 26.4 & $25.7-27.0$ & 0.24 \\
\hline \multicolumn{9}{|l|}{ Nativity } \\
\hline 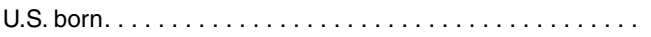 & 14,767 & $\dagger 81.7$ & $81.0-82.4$ & 0.37 & 53,629 & 80.5 & $80.0-81.1$ & 0.28 \\
\hline Foreign born $\ldots \ldots \ldots \ldots \ldots \ldots \ldots \ldots \ldots \ldots \ldots$ & 3,307 & $\dagger 18.3$ & $17.0-19.7$ & 0.37 & 12,952 & 19.5 & $18.8-20.1$ & 0.28 \\
\hline \multicolumn{9}{|l|}{ Veteran status } \\
\hline 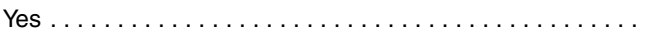 & 1,794 & 9.9 & $8.6-11.4$ & 0.23 & 6,538 & 9.8 & $9.1-10.6$ & 0.14 \\
\hline 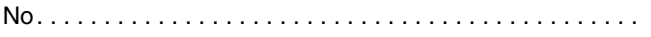 & 16,277 & 90.1 & $89.6-90.5$ & 0.23 & 60,043 & 90.2 & $89.9-90.4$ & 0.14 \\
\hline \multicolumn{9}{|l|}{ Own or rent residence } \\
\hline Own or buying $\ldots .$. & 9,899 & $\dagger 54.8$ & $53.7-56.0$ & 0.59 & 39,107 & 58.8 & $57.9-59.7$ & 0.44 \\
\hline Rent or other. $\ldots \ldots \ldots \ldots \ldots \ldots \ldots \ldots \ldots \ldots$ & 8,150 & $\dagger 45.2$ & $44.0-46.3$ & 0.59 & 27,407 & 41.2 & $40.3-42.1$ & 0.44 \\
\hline \multicolumn{9}{|l|}{ Region of residence } \\
\hline Northeast ... & 2,921 & 16.2 & $14.8-17.5$ & 0.39 & 10,900 & 16.4 & $15.7-17.1$ & 0.31 \\
\hline$\ldots \ldots \ldots \ldots \ldots \ldots \ldots$ & 4,037 & 22.3 & 21.1-23.6 & 0.51 & 14,415 & 21.6 & $20.9-22.4$ & 0.39 \\
\hline 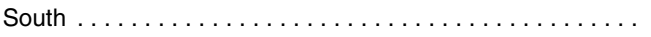 & 6,525 & 36.1 & $34.9-37.3$ & 0.53 & 24,037 & 36.1 & $35.3-36.9$ & 0.41 \\
\hline West $\ldots \ldots \ldots \ldots \ldots \ldots \ldots \ldots$ & 4,596 & 25.4 & $24.2-26.7$ & 0.60 & 17,254 & 25.9 & $24.9-26.9$ & 0.52 \\
\hline \multicolumn{9}{|l|}{ MSA status } \\
\hline 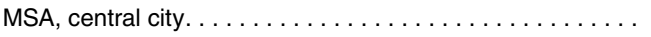 & 6,980 & 38.6 & $36.8-40.4$ & 0.90 & 24,888 & 37.4 & $35.7-39.1$ & 0.86 \\
\hline 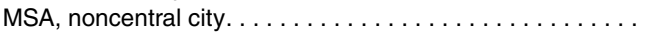 & 7,791 & 43.1 & $41.4-44.8$ & 0.88 & 29,219 & 43.9 & $42.3-45.4$ & 0.81 \\
\hline 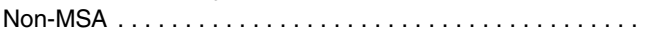 & 3,308 & 18.3 & $16.5-20.3$ & 0.96 & 12,499 & 18.8 & $16.9-20.8$ & 0.99 \\
\hline \multicolumn{9}{|l|}{ Reported health status } \\
\hline Poor or fair . . . . . . . . & 2,839 & $\dagger 15.7$ & $14.4-17.1$ & 0.30 & 9,903 & 14.9 & $14.2-15.6$ & 0.20 \\
\hline Good. . . . . . . . . . . . . . . . . & 5,007 & 27.7 & $26.5-29.0$ & 0.36 & 18,440 & 27.7 & $27.1-28.4$ & 0.22 \\
\hline Very good or excellent $\ldots \ldots \ldots \ldots \ldots \ldots$ & 10,224 & 56.6 & $55.6-57.5$ & 0.43 & 38,228 & 57.4 & $56.8-58.0$ & 0.30 \\
\hline \multicolumn{9}{|l|}{ Serious psychological distress } \\
\hline$\ldots \ldots \ldots \ldots$ & 688 & †3.8 & $2.5-5.5$ & 0.15 & 2,327 & 3.5 & $2.8-4.3$ & 0.08 \\
\hline No $\ldots \ldots \ldots \ldots \ldots \ldots \ldots \ldots \ldots \ldots$ & 17,289 & 96.2 & $95.9-96.5$ & 0.15 & 63,870 & 96.5 & $96.3-96.6$ & 0.08 \\
\hline
\end{tabular}


Table 1. Comparison of American Community Survey and Washington Group Short Set on Functioning sample adults with all sample adults (unweighted)-Con.

\begin{tabular}{|c|c|c|c|c|c|c|c|c|}
\hline \multirow[b]{2}{*}{ Variable } & \multicolumn{4}{|c|}{ ACS and WG-SS sample adults $(n=18,079)$} & \multicolumn{4}{|c|}{ All sample adults $(n=66,606)$} \\
\hline & Number & Percent & $95 \% \mathrm{Cl}$ & SE & Number & Percent & $95 \% \mathrm{Cl}$ & SE \\
\hline \multicolumn{9}{|l|}{ Cognitive difficulty } \\
\hline Yes ...... & 822 & $\dagger 4.5$ & $3.2-6.2$ & 0.18 & 2,607 & 3.9 & $3.2-4.7$ & 0.10 \\
\hline No.......... & 17,251 & †95.5 & $95.1-95.8$ & 0.18 & 63,997 & 96.1 & $95.9-96.3$ & 0.10 \\
\hline \multicolumn{9}{|l|}{ Multiple chronic conditions } \\
\hline Yes. & 5,370 & 29.9 & $28.7-31.1$ & 0.39 & 18,608 & 28.4 & $27.7-29.0$ & 0.25 \\
\hline 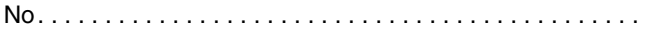 & 12,598 & 70.1 & $69.3-70.9$ & 0.39 & 46,952 & 71.6 & $71.1-72.1$ & 0.25 \\
\hline \multicolumn{9}{|l|}{ Language of interview } \\
\hline English $\ldots \ldots \ldots \ldots \ldots \ldots \ldots \ldots$ & 16,898 & †93.5 & 93.0-93.9 & 0.25 & 61,570 & 92.5 & 92.0-92.9 & 0.21 \\
\hline 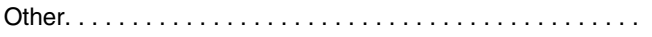 & 1,180 & †6.5 & $5.2-8.1$ & 0.25 & 5,027 & 7.5 & 6.8-8.3 & 0.21 \\
\hline \multicolumn{9}{|l|}{ Mode of interview } \\
\hline Both face to face. . . . . . . . . . & 14,528 & $\dagger 80.4$ & $79.6-81.1$ & 0.36 & 52,601 & 79.0 & $78.5-79.5$ & 0.26 \\
\hline Both telephone . . . . . . . & 2,946 & $\dagger 16.3$ & $15.0-17.7$ & 0.33 & 9,688 & 14.5 & $13.9-15.3$ & 0.22 \\
\hline 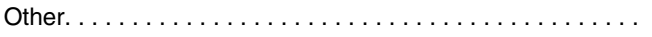 & 604 & †3.3 & $2.1-5.1$ & 0.14 & 4,308 & 6.5 & $5.7-7.2$ & 0.13 \\
\hline \multicolumn{9}{|l|}{ Speeding } \\
\hline Speeding on WG-SS & 1,000 & 5.5 & $4.2-7.1$ & 0.26 & 1,165 & 5.5 & $4.2-6.9$ & 0.23 \\
\hline Speeding on ACS . . . . . . . . . . . . . . & 1,215 & 6.7 & $5.3-8.2$ & 0.26 & 1,429 & 6.7 & $5.4-8.1$ & 0.23 \\
\hline Speeding on both $\ldots \ldots \ldots \ldots \ldots \ldots \ldots \ldots \ldots \ldots \ldots \ldots \ldots$ & 481 & 2.7 & $1.4-4.5$ & 0.17 & 577 & 2.7 & $1.6-4.4$ & 0.16 \\
\hline No speeding $\ldots \ldots \ldots \ldots \ldots \ldots \ldots \ldots \ldots \ldots$ & 15,383 & 85.1 & $84.2-86.1$ & 0.46 & 18,079 & 85.1 & $84.4-85.9$ & 0.39 \\
\hline
\end{tabular}

† Significantly different from all 2011-2012 sample adults $(p<0.05)$.

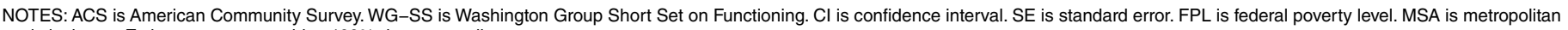
statistical area. Estimates may not add to $100 \%$ due to rounding.

SOURCE: National Center for Health Statistics, National Health Interview Survey, 2011-2012. 
Table 2. Percentage of sample with a disability according to American Community Survey and Washington Group Short Set on Functioning measures of disability $(n=18,079)$ (unweighted)

\begin{tabular}{|c|c|c|c|c|c|c|c|c|c|}
\hline \multirow[b]{2}{*}{ Variable } & \multicolumn{4}{|c|}{ WG-SS disability measure } & \multicolumn{4}{|c|}{ ACS disability measure } & \multirow{2}{*}{$\begin{array}{c}\text { ACS: WG-SS } \\
\text { ratio }\end{array}$} \\
\hline & Number & Percent & $95 \% \mathrm{Cl}$ & SE & Number & Percent & $95 \% \mathrm{Cl}$ & SE & \\
\hline Total . . . . . . . & 1,752 & 9.7 & $9.2-10.3$ & 0.26 & 3,713 & 20.5 & $19.9-21.2$ & 0.35 & 2.1 \\
\hline \multicolumn{10}{|l|}{ Age group } \\
\hline$\ldots \ldots \ldots \ldots \ldots \ldots \ldots \ldots$ & 249 & 3.2 & 2.8-3.6 & 0.20 & 640 & 8.1 & $7.5-8.8$ & 0.33 & 2.6 \\
\hline $45-64 \ldots \ldots \ldots \ldots \ldots \ldots \ldots \ldots \ldots$ & 711 & 11.6 & $10.7-12.5$ & 0.44 & 1,474 & 23.8 & $22.7-25.0$ & 0.58 & 2.1 \\
\hline 65 and over. . . . . . . . . . . . & 792 & 19.8 & $18.4-21.3$ & 0.71 & 1,599 & 39.8 & $38.1-41.5$ & 0.85 & 2.0 \\
\hline \multicolumn{10}{|l|}{ Sex } \\
\hline Male .... & 597 & 8.0 & $7.3-8.7$ & 0.34 & 1,473 & 19.6 & $18.7-20.6$ & 0.50 & 2.5 \\
\hline$\ldots \ldots \ldots \ldots \ldots$ & 1,155 & 11.0 & $10.3-11.6$ & 0.33 & 2,240 & 21.2 & $20.3-22.1$ & 0.43 & 1.9 \\
\hline \multicolumn{10}{|l|}{ Hispanic origin and race } \\
\hline Hispanic $\ldots \ldots \ldots \ldots \ldots \ldots$. & 249 & 8.5 & $7.5-9.6$ & 0.53 & 471 & 16.1 & $14.7-17.6$ & 0.72 & 1.9 \\
\hline Non-Hispanic white. . . . . . . . . . . . . & 1,063 & 9.8 & $9.2-10.5$ & 0.33 & 2,336 & 21.4 & $20.6-22.3$ & 0.45 & 2.2 \\
\hline Non-Hispanic black. . . . . . . . . . . . . . . & 338 & 11.9 & $10.6-13.2$ & 0.66 & 703 & 24.5 & $22.8-26.3$ & 0.87 & 2.1 \\
\hline Non-Hispanic, other races $\ldots \ldots \ldots \ldots$ & 102 & 7.4 & $6.0-8.9$ & 0.72 & 203 & 14.6 & $12.8-16.6$ & 0.95 & 2.0 \\
\hline \multicolumn{10}{|l|}{ Education } \\
\hline Less than high school. . . . . . . . . . . . . . . & 529 & 18.9 & $17.4-20.4$ & 0.77 & 984 & 34.9 & 33.0-36.9 & 0.99 & 1.9 \\
\hline High school diploma or GED . . . . . . . . . & 511 & 11.6 & $10.6-12.6$ & 0.49 & 1,063 & 24.0 & $22.6-25.3$ & 0.68 & 2.1 \\
\hline Some college or associate's degree. . . . . . & 502 & 8.8 & $8.0-9.6$ & 0.40 & 1,111 & 19.3 & $18.2-20.3$ & 0.52 & 2.2 \\
\hline Bachelor's degree or higher . . . . . . . . . . & 202 & 4.0 & $3.5-4.6$ & 0.29 & 539 & 10.8 & $9.9-11.6$ & 0.44 & 2.7 \\
\hline \multicolumn{10}{|l|}{ Employment status } \\
\hline$\ldots \ldots \ldots \ldots \ldots \ldots \ldots$ & 272 & 2.7 & 2.3-3.0 & 0.17 & 832 & 8.2 & $7.6-8.7$ & 0.29 & 3.0 \\
\hline Not employed $\ldots \ldots \ldots \ldots \ldots \ldots \ldots$ & 1,479 & 18.8 & $17.8-19.8$ & 0.49 & 2,877 & 36.3 & $35.1-37.6$ & 0.61 & 1.9 \\
\hline \multicolumn{10}{|l|}{ Poverty status } \\
\hline Less than $100 \%$ FPL $\ldots \ldots \ldots \ldots \ldots \ldots$ & 517 & 14.4 & $13.2-15.8$ & 0.65 & 1,009 & 28.0 & $26.4-29.7$ & 0.83 & 1.9 \\
\hline $100 \%-199 \%$ FPL $\ldots \ldots \ldots \ldots \ldots \ldots$ & 487 & 12.5 & $11.4-13.8$ & 0.60 & 1,002 & 25.7 & $24.2-27.3$ & 0.78 & 2.1 \\
\hline $200 \%-399 \%$ FPL $\ldots \ldots \ldots \ldots \ldots \ldots$ & 470 & 9.1 & $8.3-10.0$ & 0.44 & 1,004 & 19.4 & $18.1-20.6$ & 0.62 & 2.1 \\
\hline $400 \%$ or more $\mathrm{FPL} \ldots \ldots \ldots \ldots \ldots$ & 279 & 5.2 & $4.6-5.9$ & 0.32 & 698 & 12.9 & $12.0-13.9$ & 0.49 & 2.5 \\
\hline \multicolumn{10}{|l|}{ Marital status } \\
\hline Never married $\ldots \ldots \ldots \ldots \ldots \ldots \ldots$ & 292 & 6.2 & $5.5-7.0$ & 0.36 & 651 & 13.8 & $12.7-14.9$ & 0.54 & 2.2 \\
\hline Married or living with partner . . . . . . . . & 463 & 6.5 & $5.9-7.1$ & 0.29 & 1,059 & 14.7 & $13.9-15.6$ & 0.43 & 2.3 \\
\hline Divorced, separated, or widowed . . . . . . . & 990 & 16.3 & $15.3-17.4$ & 0.54 & 1,993 & 32.7 & $31.4-34.0$ & 0.67 & 2.0 \\
\hline \multicolumn{10}{|l|}{ Nativity } \\
\hline U.S. born. . . . . . . . . . . . . . . . & 1,504 & 10.2 & $9.7-10.8$ & 0.29 & 3,234 & 21.9 & $21.1-22.7$ & 0.39 & 2.1 \\
\hline Foreign born $\ldots \ldots \ldots \ldots \ldots \ldots \ldots$ & 248 & 7.5 & $6.6-8.6$ & 0.50 & 477 & 14.4 & $13.1-15.8$ & 0.67 & 1.9 \\
\hline \multicolumn{10}{|l|}{ Veteran status } \\
\hline Yes $\ldots \ldots \ldots \ldots \ldots \ldots \ldots \ldots$ & 225 & 12.7 & $11.1-14.4$ & 0.82 & 557 & 31.0 & $28.8-33.3$ & 1.14 & 2.5 \\
\hline No $\ldots \ldots \ldots \ldots \ldots \ldots \ldots \ldots$ & 1,526 & 9.4 & $8.9-9.9$ & 0.26 & 3,153 & 19.4 & $18.7-20.1$ & 0.36 & 2.1 \\
\hline \multicolumn{10}{|l|}{ Own or rent residence } \\
\hline Own or buying $\ldots \ldots \ldots \ldots \ldots \ldots$ & 810 & 8.2 & 7.7-8.8 & 0.29 & 1,912 & 19.3 & $18.5-20.2$ & 0.43 & 2.3 \\
\hline Rent or other. . . . . . . . . . . . . . & 938 & 11.6 & $10.7-12.4$ & 0.42 & 1,797 & 22.1 & $21.0-23.2$ & 0.56 & 1.9 \\
\hline \multicolumn{10}{|l|}{ Region of residence } \\
\hline Northeast $\ldots \ldots \ldots \ldots \ldots \ldots \ldots \ldots$ & 282 & 9.7 & $8.5-11.1$ & 0.66 & 636 & 21.8 & $20.1-23.5$ & 0.87 & 2.2 \\
\hline Midwest $\ldots \ldots \ldots \ldots \ldots \ldots \ldots \ldots$ & 370 & 9.2 & $8.2-10.4$ & 0.55 & 815 & 20.2 & $18.7-21.8$ & 0.79 & 2.2 \\
\hline South $\ldots \ldots \ldots \ldots \ldots \ldots$ & 694 & 10.7 & $9.8-11.5$ & 0.43 & 1,430 & 21.9 & $20.8-23.1$ & 0.59 & 2.1 \\
\hline West $\ldots \ldots \ldots \ldots \ldots \ldots \ldots \ldots$ & 406 & 8.9 & $7.9-9.9$ & 0.50 & 832 & 18.1 & $16.8-19.5$ & 0.68 & 2.0 \\
\hline \multicolumn{10}{|l|}{ MSA status } \\
\hline MSA, central city. . . . . . . . . . . & 666 & 9.6 & $8.8-10.4$ & 0.41 & 1,405 & 20.1 & $19.1-21.2$ & 0.54 & 2.1 \\
\hline MSA, noncentral city . . . . . . . . . . . & 657 & 8.5 & $7.8-9.2$ & 0.36 & 1,405 & 18.0 & $17.1-19.0$ & 0.50 & 2.1 \\
\hline Non-MSA $\ldots \ldots \ldots \ldots \ldots \ldots \ldots$ & 429 & 13.0 & $11.8-14.3$ & 0.65 & 903 & 27.3 & $25.5-29.2$ & 0.93 & 2.1 \\
\hline Reported health status & & & & & & & & & \\
\hline Poor or fair $\ldots \ldots \ldots \ldots \ldots \ldots \ldots \ldots$ & 1,007 & 35.8 & $33.9-37.6$ & 0.93 & 1,733 & 61.1 & $59.2-62.9$ & 0.93 & 1.7 \\
\hline Good. $\ldots \ldots \ldots \ldots \ldots \ldots \ldots \ldots$ & 452 & 9.1 & $8.3-9.9$ & 0.42 & 1,135 & 22.7 & $21.5-23.9$ & 0.62 & 2.5 \\
\hline Very good or excellent $\ldots \ldots \ldots \ldots \ldots$ & 290 & 2.8 & $2.5-3.2$ & 0.17 & 842 & 8.2 & 7.7-8.8 & 0.29 & 2.9 \\
\hline Serious psychological distress & & & & & & & & & \\
\hline Yes $\ldots \ldots \ldots \ldots \ldots \ldots \ldots \ldots$ & 291 & 42.4 & $38.6-46.3$ & 1.92 & 448 & 65.1 & $61.4-68.7$ & 1.84 & 1.5 \\
\hline No $\ldots \ldots \ldots \ldots \ldots \ldots \ldots \ldots$ & 1,436 & 8.3 & $7.9-8.9$ & 0.25 & 3,220 & 18.6 & $17.9-19.3$ & 0.35 & 2.2 \\
\hline
\end{tabular}


Table 2. Percentage of sample with a disability according to American Community Survey and Washington Group Short Set on Functioning measures of disability $(n=18,079)$ (unweighted)-Con.

\begin{tabular}{|c|c|c|c|c|c|c|c|c|c|}
\hline \multirow[b]{2}{*}{ Variable } & \multicolumn{4}{|c|}{ WG-SS disability measure } & \multicolumn{4}{|c|}{ ACS disability measure } & \multirow{2}{*}{$\begin{array}{c}\text { ACS: } W G-S S \\
\text { ratio }\end{array}$} \\
\hline & Number & Percent & $95 \% \mathrm{Cl}$ & SE & Number & Percent & $95 \% \mathrm{Cl}$ & SE & \\
\hline \multicolumn{10}{|l|}{ Cognitive difficulty } \\
\hline Yes $\ldots \ldots \ldots \ldots \ldots \ldots \ldots$ & 430 & 52.8 & $49.3-56.2$ & 1.71 & 2,971 & 90.3 & $88.0-92.2$ & 1.04 & 2.2 \\
\hline 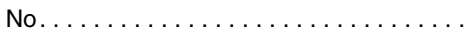 & 1,436 & 7.7 & 7.3-8.2 & 0.25 & 741 & 17.2 & $16.6-17.9$ & 0.35 & 1.7 \\
\hline \multicolumn{10}{|l|}{ Multiple chronic conditions } \\
\hline 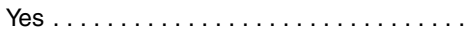 & 1,235 & 23.1 & $21.9-24.4$ & 0.64 & 2,336 & 43.5 & $42.0-45.0$ & 0.75 & 1.9 \\
\hline No. $\ldots \ldots \ldots \ldots \ldots \ldots \ldots \ldots$ & 503 & 4.0 & $3.7-4.4$ & 0.18 & 1,342 & 10.7 & $10.1-11.3$ & 0.31 & 2.7 \\
\hline \multicolumn{10}{|l|}{ Language of interview } \\
\hline English $\ldots \ldots \ldots \ldots \ldots \ldots \ldots$ & 1,614 & 9.6 & $9.1-10.1$ & 0.26 & 3,502 & 20.7 & $20.0-21.5$ & 0.36 & 2.2 \\
\hline Other. . . . . . . . $\ldots \ldots \ldots \ldots$ & 138 & 11.7 & $9.8-13.8$ & 1.00 & 211 & 17.9 & 15.5-20.4 & 1.23 & 1.5 \\
\hline \multicolumn{10}{|l|}{ Mode of interview } \\
\hline Both face to face . . . . . . . . . . & 1,486 & 10.3 & $9.7-10.9$ & 0.30 & 3,147 & 21.7 & $20.9-22.5$ & 0.40 & 2.1 \\
\hline Both telephone $\ldots \ldots \ldots \ldots \ldots \ldots$ & 225 & 7.7 & $6.8-8.7$ & 0.49 & 474 & 16.1 & $14.7-17.5$ & 0.71 & 2.1 \\
\hline Other. .............. & 41 & 6.9 & $4.8-9.4$ & 1.10 & 92 & 15.2 & $12.3-18.5$ & 1.53 & 2.2 \\
\hline \multicolumn{10}{|l|}{ Speeding } \\
\hline Speeding on WG-SS $\ldots \ldots \ldots \ldots \ldots$ & 16 & 1.6 & $0.9-2.6$ & 0.38 & 96 & 9.6 & $7.2-11.2$ & 0.93 & 5.9 \\
\hline Speeding on ACS . . . . . . . . . . . & 69 & 5.7 & $4.4-7.2$ & 0.68 & 77 & 6.3 & $5.1-8.4$ & 0.75 & 1.1 \\
\hline Speeding on both $\ldots \ldots \ldots \ldots \ldots \ldots$ & 1 & 0.2 & $0.0-1.5$ & 0.21 & 6 & 1.2 & $0.5-2.9$ & 0.51 & 6.0 \\
\hline No speeding $\ldots \ldots \ldots \ldots \ldots \ldots \ldots$ & 1,666 & 10.9 & $10.3-11.5$ & 0.29 & 3,534 & 23.0 & $22.2-23.8$ & 0.40 & 2.1 \\
\hline
\end{tabular}

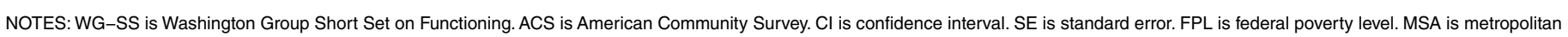
statistical area.

SOURCE: National Center for Health Statistics, National Health Interview Survey, 2011-2012. 
Table 3. Characteristics of adults, by disability measure (unweighted)

\begin{tabular}{|c|c|c|c|c|c|c|c|c|}
\hline \multirow[b]{2}{*}{ Variable } & \multicolumn{4}{|c|}{ WG-SS disability measure } & \multicolumn{4}{|c|}{ ACS disability measure } \\
\hline & Number & Percent & $95 \% \mathrm{Cl}$ & SE & Number & Percent & $95 \% \mathrm{Cl}$ & SE \\
\hline \multicolumn{9}{|l|}{ Age group } \\
\hline $18-44 \ldots \ldots \ldots \ldots \ldots \ldots \ldots \ldots \ldots \ldots \ldots$ & 249 & $\dagger 14.2$ & $10.1-19.2$ & 0.86 & 640 & 17.2 & $14.4-20.4$ & 0.70 \\
\hline $45-64 \ldots \ldots \ldots \ldots \ldots \ldots \ldots \ldots \ldots \ldots$ & 711 & 40.6 & $36.9-44.3$ & 1.28 & 1,474 & 39.7 & $37.2-42.2$ & 0.86 \\
\hline 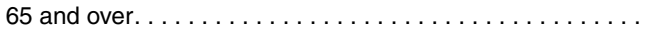 & 792 & $\dagger 45.2$ & $41.7-48.7$ & 1.34 & 1,599 & 43.1 & $40.6-45.5$ & 0.89 \\
\hline \multicolumn{9}{|l|}{ Sex } \\
\hline Male ....... & 597 & $\dagger 34.1$ & $30.3-38.0$ & 1.14 & 1,473 & 39.7 & $37.2-42.2$ & 0.81 \\
\hline Female $\ldots \ldots \ldots \ldots \ldots \ldots \ldots \ldots \ldots$ & 1,155 & $\dagger 65.9$ & $63.1-68.7$ & 1.14 & 2,240 & 60.3 & $58.3-62.4$ & 0.81 \\
\hline \multicolumn{9}{|l|}{ Hispanic origin and race } \\
\hline Hispanic . . . . . . . . . . . . . . . . & 249 & $\dagger 14.2$ & $10.1-19.2$ & 0.87 & 471 & 12.7 & $9.8-16.0$ & 0.61 \\
\hline Non-Hispanic white $\ldots \ldots \ldots \ldots \ldots \ldots \ldots \ldots$ & 1,063 & $\dagger 60.7$ & $57.7-63.6$ & 1.30 & 2,336 & 62.9 & $60.9-64.9$ & 0.90 \\
\hline 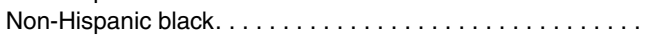 & 338 & 19.3 & $15.2-23.9$ & 1.09 & 703 & 18.9 & $16.1-22.0$ & 0.75 \\
\hline Non-Hispanic, other races $\ldots \ldots \ldots \ldots \ldots \ldots \ldots$ & 102 & 5.8 & $2.2-12.3$ & 0.56 & 203 & 5.5 & $2.8-9.5$ & 0.39 \\
\hline \multicolumn{9}{|l|}{ Education } \\
\hline Less than high school. . . . . . . . . . . . . . . . & 529 & $\dagger 30.3$ & $26.4-34.5$ & 1.12 & 984 & 26.6 & 23.9-29.5 & 0.80 \\
\hline High school diploma or GED $\ldots \ldots \ldots \ldots \ldots \ldots \ldots$ & 511 & 29.3 & $25.4-33.5$ & 1.11 & 1,063 & 28.8 & 26.0-31.6 & 0.80 \\
\hline Some college or associate's degree $\ldots \ldots \ldots \ldots \ldots \ldots$ & 502 & 28.8 & $24.9-33.0$ & 1.17 & 1,111 & 30.1 & $27.4-32.8$ & 0.78 \\
\hline Bachelor's degree or higher $\ldots \ldots \ldots \ldots \ldots \ldots \ldots \ldots$ & 202 & $\dagger 11.6$ & $7.5-16.8$ & 0.79 & 539 & 14.6 & $11.7-17.8$ & 0.60 \\
\hline \multicolumn{9}{|l|}{ Employment status } \\
\hline Employed . . . . . . . . . . . . . . & 272 & $\dagger 15.5$ & $11.2-20.1$ & 0.90 & 832 & 22.4 & $19.4-25.2$ & 0.74 \\
\hline Not employed $\ldots \ldots \ldots \ldots \ldots \ldots \ldots \ldots \ldots \ldots \ldots \ldots$ & 1,479 & $\dagger 84.5$ & $82.8-86.5$ & 0.90 & 2,877 & 77.6 & $76.2-79.3$ & 0.74 \\
\hline \multicolumn{9}{|l|}{ Poverty status } \\
\hline Less than $100 \%$ FPL $\ldots \ldots \ldots \ldots \ldots$ & 517 & $\dagger 29.5$ & $25.6-33.7$ & 1.18 & 1,009 & 27.2 & 24.4-30.0 & 0.79 \\
\hline$\ldots \ldots \ldots \ldots \ldots \ldots \ldots$ & 487 & 27.8 & $23.8-32.0$ & 1.16 & 1,002 & 27.0 & 24.3-29.9 & 0.78 \\
\hline $200 \%-399 \%$ FPL $\ldots \ldots \ldots \ldots \ldots \ldots \ldots \ldots$ & 470 & 26.8 & $22.8-31.1$ & 1.15 & 1,004 & 27.0 & 24.3-29.9 & 0.86 \\
\hline $400 \%$ or more $\mathrm{FPL} \ldots \ldots \ldots \ldots \ldots \ldots \ldots \ldots$ & 279 & 15.9 & $11.8-20.7$ & 0.93 & 698 & 18.8 & $16.0-21.9$ & 0.72 \\
\hline \multicolumn{9}{|l|}{ Marital status } \\
\hline Never married $\ldots \ldots \ldots \ldots \ldots \ldots \ldots \ldots \ldots$ & 292 & 16.7 & $12.6-21.5$ & 0.91 & 651 & 17.6 & $14.7-20.7$ & 0.69 \\
\hline Married or living with partner $\ldots \ldots \ldots \ldots \ldots \ldots$ & 463 & $\dagger 26.5$ & $22.6-30.8$ & 1.08 & 1,059 & 28.6 & 25.9-31.4 & 0.75 \\
\hline Divorced, separated, or widowed $\ldots \ldots \ldots \ldots \ldots \ldots \ldots$ & 990 & $\dagger 56.7$ & $53.6-59.8$ & 1.25 & 1,993 & 53.8 & $51.6-56.0$ & 0.84 \\
\hline \multicolumn{9}{|l|}{ Nativity } \\
\hline 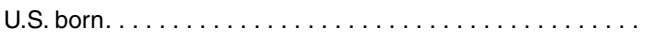 & 1,504 & 85.8 & $83.9-87.6$ & 0.93 & 3,234 & 87.1 & $85.9-88.3$ & 0.63 \\
\hline Foreign born $\ldots \ldots \ldots \ldots \ldots \ldots \ldots \ldots \ldots \ldots$ & 248 & $\dagger 14.2$ & $10.1-19.1$ & 0.93 & 477 & 12.9 & $10.0-16.2$ & 0.63 \\
\hline \multicolumn{9}{|l|}{ Veteran status } \\
\hline Yes $\ldots \ldots \ldots \ldots \ldots \ldots \ldots \ldots \ldots \ldots$ & 225 & $\dagger 12.8$ & $8.8-17.9$ & 0.80 & 557 & 15.0 & $12.1-18.3$ & 0.61 \\
\hline 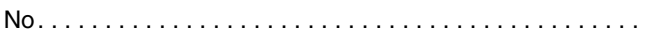 & 1,526 & $\dagger 87.2$ & $85.4-88.8$ & 0.80 & 3,153 & 85.0 & $83.7-86.2$ & 0.61 \\
\hline \multicolumn{9}{|l|}{ Own or rent residence } \\
\hline 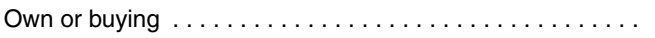 & 810 & $\dagger 46.3$ & $42.9-49.8$ & 1.33 & 1,912 & 51.6 & $49.3-53.8$ & 1.00 \\
\hline 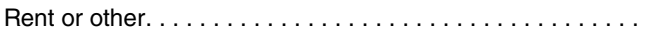 & 938 & $\dagger 53.7$ & $50.4-56.9$ & 1.33 & 1,797 & 48.4 & $46.1-50.8$ & 1.00 \\
\hline \multicolumn{9}{|l|}{ Region of residence } \\
\hline 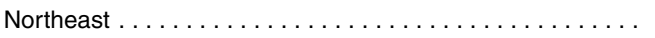 & 282 & 16.1 & 12.0-20.9 & 1.06 & 636 & 17.1 & $14.3-20.3$ & 0.75 \\
\hline Midwest $\ldots \ldots \ldots \ldots \ldots \ldots \ldots \ldots \ldots$ & 370 & 21.1 & $17.1-25.6$ & 1.25 & 815 & 21.9 & $19.2-25.0$ & 0.91 \\
\hline 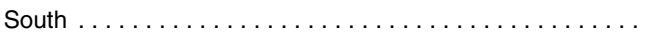 & 694 & 39.6 & $36.0-43.4$ & 1.43 & 1,430 & 38.5 & $36.0-41.1$ & 1.02 \\
\hline West $\ldots \ldots \ldots \ldots \ldots \ldots \ldots \ldots \ldots \ldots$ & 406 & 23.2 & $19.2-27.6$ & 1.27 & 832 & 22.4 & $19.6-25.4$ & 0.95 \\
\hline \multicolumn{9}{|l|}{ MSA status } \\
\hline MSA, central city. $\ldots \ldots \ldots \ldots \ldots \ldots \ldots \ldots$ & 666 & 38.0 & $34.3-41.8$ & 1.49 & 1,405 & 37.8 & $35.3-40.4$ & 1.19 \\
\hline 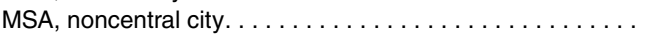 & 657 & 37.5 & $33.8-41.3$ & 1.53 & 1,405 & 37.8 & $35.3-40.4$ & 1.22 \\
\hline Non-MSA $\ldots \ldots \ldots \ldots \ldots \ldots \ldots \ldots \ldots \ldots \ldots$ & 429 & 24.5 & $20.5-28.8$ & 1.54 & 903 & 24.3 & $21.6-27.3$ & 1.40 \\
\hline Reported health status & & & & & & & & \\
\hline Poor or fair $\ldots \ldots \ldots \ldots \ldots \ldots \ldots \ldots \ldots$ & 1,007 & $\dagger 57.6$ & $54.5-60.7$ & 1.25 & 1,733 & 46.7 & $44.3-49.1$ & 0.88 \\
\hline Good. $\ldots \ldots \ldots \ldots \ldots \ldots \ldots \ldots$ & 452 & $\dagger 25.8$ & $21.9-30.1$ & 1.03 & 1,135 & 30.6 & 27.9-33.4 & 0.76 \\
\hline Very good or excellent $\ldots \ldots \ldots \ldots \ldots \ldots \ldots$ & 290 & $\dagger 16.6$ & $12.5-21.4$ & 0.87 & 842 & 22.7 & $19.9-25.7$ & 0.69 \\
\hline Serious psychological distress & & & & & & & & \\
\hline 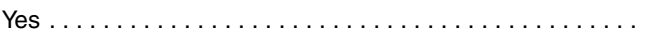 & 291 & $\dagger 16.9$ & $12.7-21.7$ & 0.94 & 448 & 12.2 & $9.3-15.6$ & 0.56 \\
\hline 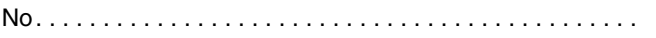 & 1,436 & $\dagger 83.1$ & $81.1-85.1$ & 0.94 & 3,220 & 87.8 & $86.6-88.9$ & 0.56 \\
\hline Cognitive difficulty & & & & & & & & \\
\hline$\ldots \ldots \ldots \ldots \ldots$ & 430 & $\dagger 24.6$ & $20.6-28.9$ & 1.04 & 741 & 20.0 & $17.1-23.0$ & 0.67 \\
\hline 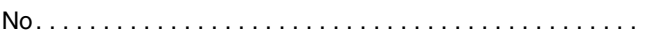 & 1,321 & $\dagger 75.4$ & $73.0-77.7$ & 1.04 & 2,971 & 80.0 & $78.5-81.5$ & 0.67 \\
\hline
\end{tabular}

See footnotes at end of table. 
Table 3. Characteristics of adults, by disability measure (unweighted)—Con.

\begin{tabular}{|c|c|c|c|c|c|c|c|c|}
\hline \multirow[b]{2}{*}{ Variable } & \multicolumn{4}{|c|}{ WG-SS disability measure } & \multicolumn{4}{|c|}{ ACS disability measure } \\
\hline & Number & Percent & $95 \% \mathrm{Cl}$ & SE & Number & Percent & $95 \% \mathrm{Cl}$ & SE \\
\hline \multicolumn{9}{|l|}{ Multiple chronic conditions } \\
\hline 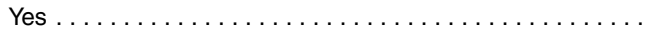 & 1,235 & $\dagger 71.1$ & $68.4-73.6$ & 1.14 & 2,336 & 63.5 & $61.5-65.5$ & 0.90 \\
\hline 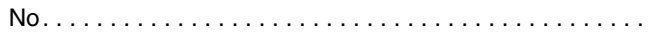 & 503 & $\dagger 28.9$ & $25.0-33.1$ & 1.14 & 1,342 & 36.5 & 33.9-39.1 & 0.90 \\
\hline \multicolumn{9}{|l|}{ Language of interview } \\
\hline$\ldots \ldots \ldots \ldots \ldots$ & 1,614 & †92.1 & $90.6-93.5$ & 0.71 & 3,502 & 94.3 & $93.4-95.1$ & 0.44 \\
\hline 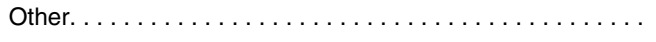 & 138 & $\dagger 7.9$ & $4.0-13.7$ & 0.71 & 211 & 5.7 & 3.0-9.7 & 0.44 \\
\hline \multicolumn{9}{|l|}{ Mode of interview } \\
\hline 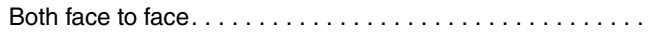 & 1,486 & 84.8 & $82.9-86.6$ & 0.92 & 3,147 & 84.8 & $83.5-86.0$ & 0.64 \\
\hline Both telephone $\ldots \ldots \ldots \ldots \ldots \ldots \ldots \ldots \ldots$ & 225 & 12.8 & $8.8-17.9$ & 0.83 & 474 & 12.8 & $9.9-16.1$ & 0.59 \\
\hline 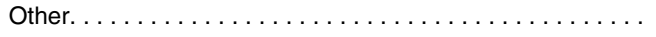 & 41 & 2.3 & $1.6-3.2$ & 0.39 & 92 & 2.5 & 2.0-3.1 & 0.27 \\
\hline \multicolumn{9}{|l|}{ Speeding } \\
\hline Speeding on WG-SS $\ldots \ldots \ldots \ldots \ldots \ldots$ & 16 & †0.9 & $0.5-1.5$ & 0.23 & 96 & 2.6 & $2.1-3.2$ & 0.29 \\
\hline Speeding on ACS $\ldots \ldots \ldots \ldots \ldots \ldots \ldots \ldots \ldots \ldots \ldots \ldots \ldots \ldots \ldots$ & 69 & †3.9 & $3.1-5.0$ & 0.47 & 77 & 2.1 & $1.6-2.6$ & 0.26 \\
\hline Speeding on both $\ldots \ldots \ldots \ldots \ldots \ldots \ldots \ldots \ldots$ & 1 & 0.1 & $0.0-0.3$ & 0.06 & 6 & 0.2 & $0.1-0.4$ & 0.07 \\
\hline No speeding $\ldots \ldots \ldots \ldots \ldots \ldots \ldots \ldots \ldots \ldots$ & 1,666 & 95.1 & $94.0-96.2$ & 0.52 & 3,534 & 95.2 & $94.3-95.9$ & 0.40 \\
\hline
\end{tabular}

† Significantly different from ACS measure percentage $(p<0.05)$.

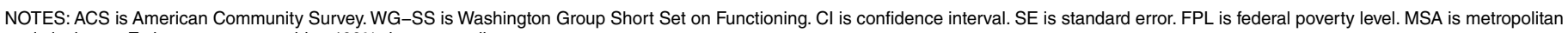
statistical area. Estimates may not add to $100 \%$ due to rounding.

SOURCE: National Center for Health Statistics, National Health Interview Survey, 2011-2012. 
Table 4. American Community Survey disability measure by Washington Group Short Set on Functioning disability measure among sample adults who were also family respondents and completed both sets of questions (unweighted)

\begin{tabular}{|c|c|c|c|}
\hline \multirow[b]{2}{*}{ ACS disability measure } & \multicolumn{2}{|c|}{ WG-SS disability measure } & \multirow[b]{2}{*}{ Total } \\
\hline & Yes & No & \\
\hline Total ... & 1,752 & 16,233 & 17,985 \\
\hline 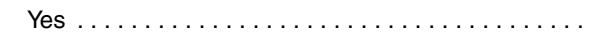 & 1,557 & 2,125 & 3,682 \\
\hline No $\ldots \ldots \ldots \ldots \ldots \ldots \ldots \ldots$ & 195 & 14,108 & 14,303 \\
\hline
\end{tabular}

Overall agreement $=0.87$

Positive agreement $=0.57$.

Negative agreement $=0.92$

Kappa statistic: 0.50 .

Prevalence-adjusted bias-adjusted kappa: 0.74

NOTES: ACS is American Community Survey. WG-SS is Washington Group Short Set on Functioning

SOURCE: National Center for Health Statistics, National Health Interview Survey, 2011-2012. 
Table 5. Multivariate logistic regression results of nonagreement between American Community Survey and Washington Group Short Set on Functioning disability measures (unweighted)

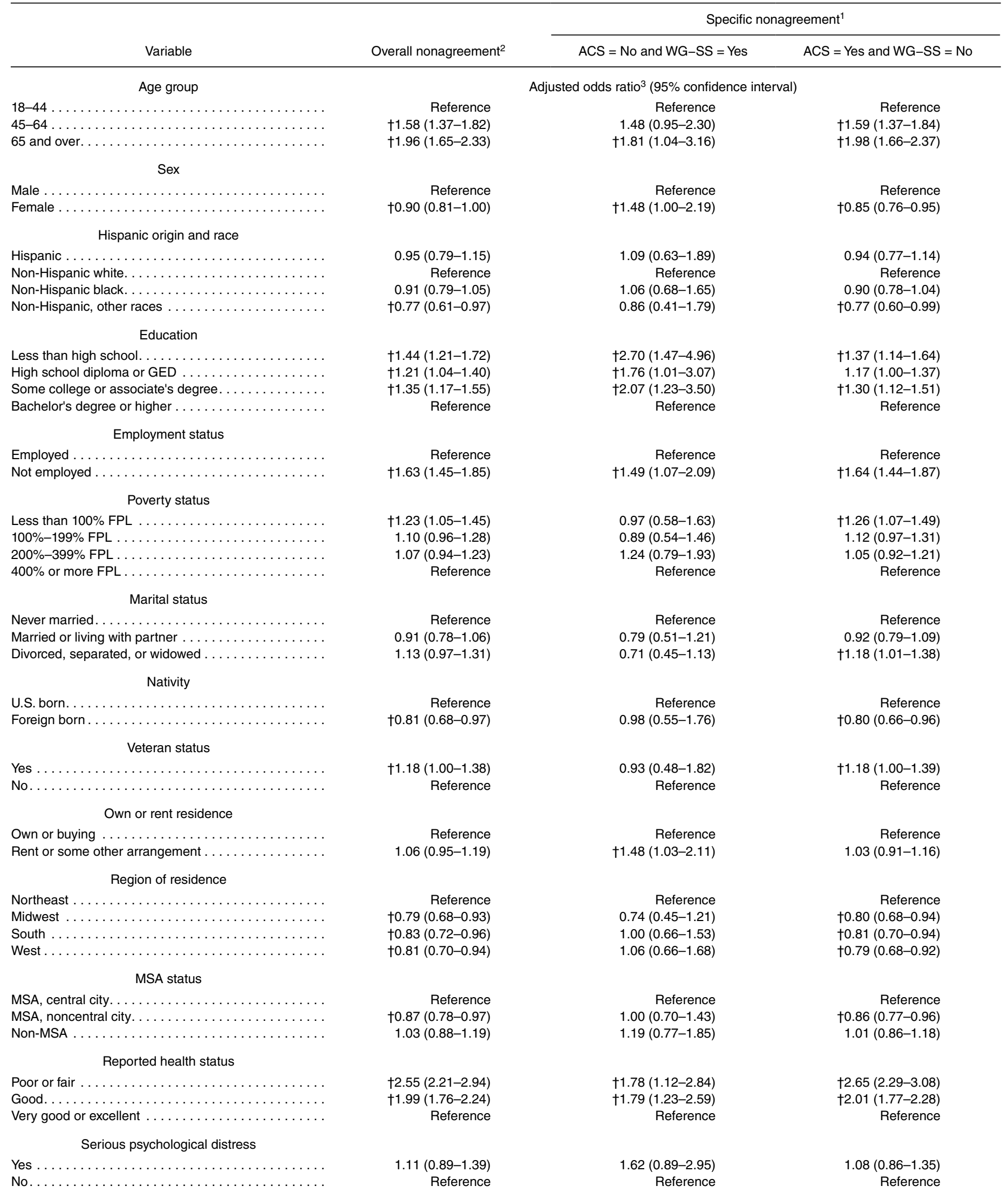


Table 5. Multivariate logistic regression results of nonagreement between American Community Survey and Washington Group Short Set on Functioning disability measures (unweighted)-Con.

\begin{tabular}{|c|c|c|c|}
\hline \multirow[b]{2}{*}{ Variable } & \multirow[b]{2}{*}{ Overall nonagreement ${ }^{2}$} & \multicolumn{2}{|c|}{ Specific nonagreement ${ }^{1}$} \\
\hline & & $A C S=$ No and $W G-S S=$ Yes & $A C S=$ Yes and WG-SS $=$ No \\
\hline Cognitive difficulty & \multicolumn{3}{|c|}{ Adjusted odds ratio ${ }^{3}$ (95\% confidence interval) } \\
\hline 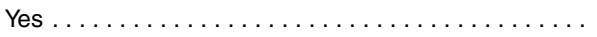 & $\dagger 1.82(1.51-2.19)$ & $0.51(0.23-1.11)$ & $\dagger 1.96(1.62-2.37)$ \\
\hline No..................... & Reference & Reference & Reference \\
\hline \multicolumn{4}{|l|}{ Multiple chronic conditions } \\
\hline Yes $\ldots \ldots \ldots \ldots \ldots \ldots \ldots \ldots \ldots$ & $\dagger 1.47(1.31-1.66)$ & $\dagger 2.05(1.41-3.00)$ & $\dagger 1.43(1.26-1.62)$ \\
\hline 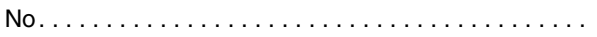 & Reference & Reference & Reference \\
\hline \multicolumn{4}{|l|}{ Language of interview } \\
\hline 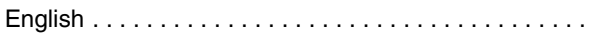 & $0.82(0.64-1.06)$ & $1.56(0.81-3.03)$ & †0.72 (0.54-0.94) \\
\hline 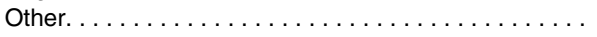 & Reference & Reference & Reference \\
\hline \multicolumn{4}{|l|}{ Mode of interview } \\
\hline Both face to face $\ldots \ldots \ldots \ldots \ldots \ldots \ldots$ & Reference & Reference & Reference \\
\hline Both telephone . . . . . . . . . . . . . . . & $0.92(0.80-1.06)$ & $1.04(0.70-1.56)$ & $0.91(0.78-1.05)$ \\
\hline Other. $\ldots \ldots \ldots \ldots \ldots \ldots \ldots \ldots \ldots \ldots$ & $0.89(0.65-1.22)$ & $0.90(0.35-2.29)$ & $0.89(0.64-1.23)$ \\
\hline \multicolumn{4}{|l|}{ Speeding } \\
\hline No speeding $\ldots \ldots \ldots \ldots \ldots \ldots \ldots \ldots \ldots$ & Reference & Reference & Reference \\
\hline Speeding on WG-SS $\ldots \ldots \ldots \ldots \ldots$ & †0.62 (0.44-0.88) & †20.14 (2.73-148.9) & †0.35 (0.23-0.52) \\
\hline Speeding on ACS $\ldots \ldots \ldots \ldots \ldots \ldots \ldots$ & †0.20 (0.10-0.42) & $2.07(0.13-33.94)$ & †0.18 (0.08-0.39) \\
\hline Speeding on both $\ldots \ldots \ldots \ldots \ldots \ldots \ldots$ & $\dagger 1.37(1.10-1.71)$ & †8.67 (1.20-62.68) & $\dagger 1.27(1.02-1.58)$ \\
\hline
\end{tabular}

† Significantly different from reference category $(p<0.05)$.

${ }^{1}$ Adjusted odds ratios from multinomial logistic regression predicting specific types of nonagreement.

${ }^{2}$ Adjusted odds ratios from binomial logistic regression predicting overall nonagreement.

${ }^{3}$ Odds ratios were adjusted for all independent variables shown in table.

NOTES: ACS is American Community Survey. WG-SS is Washington Group Short Set on Functioning. FPL is federal poverty level. MSA is metropolitan statistical area.

SOURCE: National Center for Health Statistics, National Health Interview Survey, 2011-2012. 
Table 6. American Community Survey disability measure by trichotomous Washington Group Short Set on Functioning disability measure (unweighted)

\begin{tabular}{cccrc}
\hline & \multicolumn{4}{c}{ WG-SS } \\
\cline { 2 - 5 } ACS & $\begin{array}{c}\text { A lot of difficulty or } \\
\text { unable to do }\end{array}$ & Some difficulty & No difficulty & Total \\
\hline Total $\ldots \ldots \ldots \ldots \ldots \ldots \ldots \ldots \ldots$ & 1,752 & 4,850 & 11,383 & 17,985 \\
Yes $\ldots \ldots \ldots \ldots \ldots \ldots \ldots \ldots$ & 1,557 & 1,801 & 324 & 3,682 \\
No $\ldots \ldots \ldots \ldots \ldots \ldots \ldots \ldots$ & 195 & 3,049 & 11,059 & 14,303 \\
\hline
\end{tabular}

NOTES: ACS is American Community Survey. WG-SS is Washington Group Short Set on Functioning.

SOURCE: National Center for Health Statistics, National Health Interview Survey, 2011-2012. 
Table 7. Bivariate logistic regressions of outcomes, by disability measure

\begin{tabular}{|c|c|c|c|c|}
\hline \multirow[b]{2}{*}{ Outcome } & \multirow{2}{*}{$\begin{array}{c}\text { ACS Measure } \\
\text { Yes compared with No }\end{array}$} & \multirow{2}{*}{$\begin{array}{c}\text { WG-SS Measure } \\
\text { A lot of difficulty or } \\
\text { unable to do compared } \\
\text { with Some or no difficulty }\end{array}$} & \multicolumn{2}{|c|}{ Trichotomous WG-SS Measure } \\
\hline & & & $\begin{array}{l}\text { Some difficulty } \\
\text { compared with } \\
\text { No difficulty }\end{array}$ & $\begin{array}{l}\text { A lot of difficulty or } \\
\text { unable to do compared } \\
\text { with No difficulty }\end{array}$ \\
\hline Unemployed (18-64 years) . . . . . . . . . . . & $5.40(4.88-5.98)$ & $7.43(6.35-8.68)$ & $1.97(1.80-2.15)$ & $8.94(7.62-10.47)$ \\
\hline Less than high school ( 25 years and over). & $2.48(2.25-2.72)$ & $2.64(2.36-2.94)$ & $1.75(1.58-1.93)$ & $3.22(2.85-3.63)$ \\
\hline Rent home $\ldots \ldots \ldots \ldots \ldots \ldots$ & $1.18(1.09-1.28)$ & $1.46(1.31-1.62)$ & $0.89(0.83-0.95)$ & $1.41(1.26-1.57)$ \\
\hline Less than $100 \%$ federal poverty level. . . . . & $1.73(1.58-1.89)$ & $1.82(1.63-2.04)$ & $1.18(1.08-1.28)$ & $1.91(1.70-2.15)$ \\
\hline
\end{tabular}

NOTES: ACS is American Community Survey. WG-SS is Washington Group Short Set on Functioning.

SOURCE: National Center for Health Statistics, National Health Interview Survey, 2011-2012. 


\section{U.S. DEPARTMENT OF HEALTH \& HUMAN SERVICES}

FIRST CLASS MAIL POSTAGE \& FEES PAID $\mathrm{CDC} / \mathrm{NCHS}$

Centers for Disease Control and Prevention National Center for Health Statistics

3311 Toledo Road, Room 4551, MS P08

Hyattsville, MD 20782-2064

OFFICIAL BUSINESS

PENALTY FOR PRIVATE USE, $\$ 300$

For more NCHS NHSRs, visit:

https://www.cdc.gov/nchs/products/nhsr.htm.

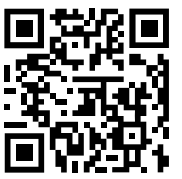

\section{Suggested citation}

Weeks JD, Dahlhamer JM, Madans JH, Maitland A. Measuring disability: An examination of differences between the Washington Group Short Set on Functioning and the American Community Survey disability questions. National Health Statistics Reports; no 161. Hyattsville, MD: National Center for Health Statistics. 2021. DOI: https://dx.doi.org/10.15620/cdc:107202.

\section{Copyright information}

All material appearing in this report is in the public domain and may be reproduced or copied without permission; citation as to source, however, is appreciated.
National Center for Health Statistics

Brian C. Moyer, Ph.D., Director

Amy M. Branum, Ph.D., Associate Director for Science

Division of Analysis and Epidemiology

Irma E. Arispe, Ph.D., Director

Kevin C. Heslin, Ph.D., Associate Director for Science

Division of Health Interview Statistics

Stephen J. Blumberg, Ph.D., Director Anjel Vahratian, Ph.D., M.P.H., Associate Director for Science

For e-mail updates on NCHS publication releases, subscribe online at: https://www.cdc.gov/nchs/email-updates.htm. For questions or general information about NCHS: Tel: 1-800-CDC-INFO (1-800-232-4636) • TTY: 1-888-232-6348 Internet: https://www.cdc.gov/nchs • Online request form: https://www.cdc.gov/info • CS325119 